\title{
Association of Chlamydia trachomatis infections with preterm delivery; a systematic review and meta-analysis
}

\author{
Amjad Ahmadi ${ }^{1,2^{*}}$, Rashid Ramazanzadeh ${ }^{1,2^{*}}$ (D) Koroush Sayehmiri $^{3}$, Fatemeh Sayehmiri ${ }^{4}$ and Nour Amirmozafari ${ }^{5}$
}

\begin{abstract}
Background: Premature birth is a primary cause of infant mortality and its etiology varies in different countries. Chlamydia trachomatis (CT) is a common infectious agent transmitted through sexual contact. The purpose of this study is to investigate the connection between $C T$ infections and preterm birth by meta-analysis.

Methods: All articles published in literature databases including Google Scholar, PubMed, ISI (Web of Science), Biological Abs, IranMedex, SID, and Scopus were investigated. Twenty-four relevant articles, authored betweenm 1998-2014 were analyzed through a random effects model. Heterogeneity of the studies was evaluated by $I^{2}$ index. The relationship between years of data collection, sample size, and CT infections with preterm delivery prevalence was examined by meta-regression. Data were analyzed with $R$ and STATA [Ver. 12].

Results: The overall prevalence of CT infections leading to preterm deliveries was estimated to be $0.13 \%$ (CI 95\%: 0 . 11-0.16). The prevalence of $C T$ infections leading to preterm deliveries were calculated based on the study method including PCR [0.06 (Cl 95\%: 0.04-0.09)], serology [0.23 (Cl 95\%: 0.10-0.35)] and culture [0.17 (Cl 95\%: 0.10-0.24)]. Analysis indicates that women with chlamydia infections were 2.28 more likely to deliver pre-term in comparison with those who were not infected. It can be concluded that chlamydia infections increase the risks of preterm delivery, $\mathrm{OR}=2.28$ (95\% Cl:1.64-3.16).

Conclusions: In regard to the results in numerous studies performed on different continents, this meta- analysis showed a clear association between preterm delivery and prior $C T$ colonization.
\end{abstract}

Keywords: Preterm delivery, Preterm labor, Chlamydia trachomatis

\section{Background}

Chlamydia trachomatis $(C T)$ is a gram-negative non-motile bacterium, $0.2-1.4 \mu \mathrm{m}$ in size, that tend to live inside the cylindrical cells of human epithelium [1]. It is the most common infection transmitted through sexual intercourse and those infected may unconsciously transmit it to their sexual partners [2]. In terms of clinical manifestations, colonization with this bacterium by in large is asymptomatic ( $80 \%$ of cases). Patients often do not seek medical treatment up until the symptoms become prominent [3]. Studies have shown that about

\footnotetext{
* Correspondence: microbiology90@gmail.com; atrop_T51@yahoo.com ${ }^{1}$ Cellular and Molecular Research Center, Research Institute for Health Development, Kurdistan University of Medical Sciences, Pasdaran Street, Sanandaj 66177-13446, Iran

Full list of author information is available at the end of the article
}

four million people in the world are infected with $C T$ [4].

Premature birth is a primary cause of infant mortality and the costs of caring for preterm infants are often high. Complications of preterm birth include hyaline membrane disease, necrotizing enterocolitis, air leak syndrome, and intraventricular hemorrhage of the brain. If the new-born survives, they may face convulsions, hearing disorders, or visual disturbances [5]. Rates of premature births vary in different societies, $5-15 \%$ in North America and 1.3\% in Iran [6, 7].

Different factors can lead to the occurrence of preterm births including heart disease, multiple birth, repeated abortions, diabetes, and genitourinary tract infections. Genitourinary infections may be responsible for $25-40 \%$ of preterm births. These infections are 
caused by bacteria such as Mycoplasma urealyticum (MU), Mycoplasma huminis (MH), Neisseria gonorrhea (NG), Trichomonas vaginalis (T. vaginalis), and Chlamydia trachomatis $(C T)$. The role of $C T$ infections in preterm birth has not been well established [8]. Several studies have been conducted on the outcome of $C T$ infections [9-31]. The aim of this investigation is to evaluate the results of these studies by meta-analysis.

\section{Methods}

\section{Literature identification}

We used PRISMA guidelines for this article [32]. Our data were based on articles that were published in local and international journals. We conducted the literature searches with the following keywords: $C T$ and preterm delivery, $C T$ and preterm labor, $C T$ and preterm birth, $C T$ and premature delivery, $C T$ and prematurity, and $C T$ and premature child birth. All medical literature published in databases including
Google Scholar, PubMed, ISI (Web of Science), Biological Abs, IranMedex, SID, and Scopus between, 1986-2014 were chosen. In the first search, 75 manuscripts published between, 1986-2014 were selected. We excluded all duplicate articles, which left 23 for analysis (Fig. 1) [33, 34].

\section{Inclusion and exclusion criteria}

All papers with the keywords from above in the title or the abstract were included in our first list and irrelevant articles were removed from the study. The search process was performed by two persons and adjusted one by one. The most important biases in meta-analysis are: publication bias and selection bias. Publication bias was checked using the Begg's test. We reduced the possibility of selection bias by clearly defining the criteria for data collection in each selected study by two researchers independently. These selected studies became the final list.

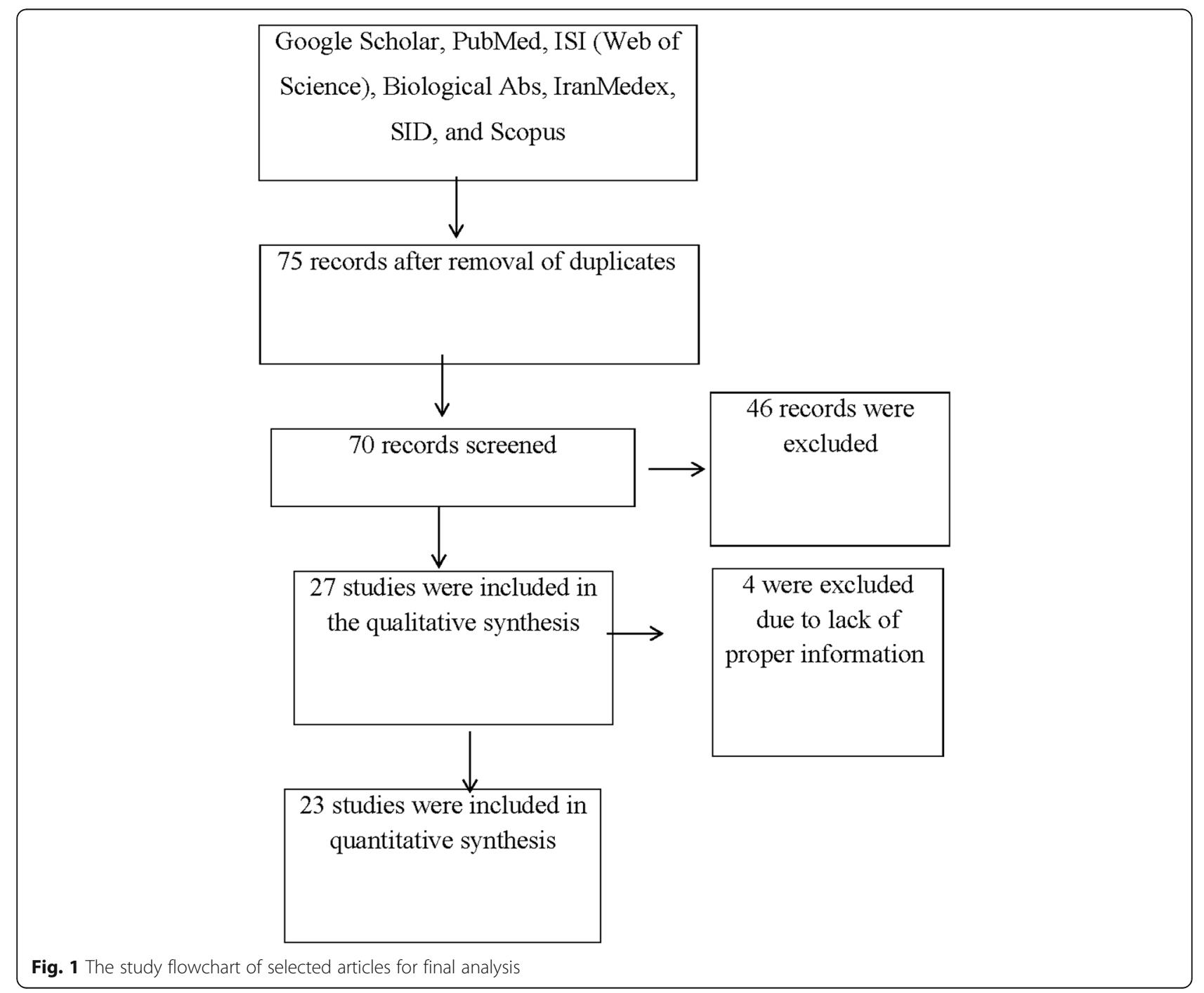




\section{Data extraction}

An information checklist for research papers consisted of first author's last name, year of publication, country where the study was carried out, mean age of participants, sample size, study period, method of bacteria identification, the type of study, and existence of a significant to no significant relationship between $C T$ infections with preterm birth. Studies were excluded if they presented insufficient data, if they were mere reviews, or if they were not epidemiologic studies.

\section{Statistical analysis}

Variance of prevalence for CT in each study were calculated as binomial distributions. Studies were combined based on their sample sizes and variance of samples. Due to the heterogeneity of the studies, the random effects model was used when combining studies. To assess heterogeneity, the Cochrane $\mathrm{Q}$ test and $\mathrm{I}^{2}$ statistics were used. A $p$-value less than $5 \%$ was considered a significant heterogeneity test. To examine publication bias, the Begg's test and funnel plot was used. A funnel plot is a graphical detection of publication bias that is actually a bivariate scatter plot $(x, y)$ of sample size versus estimates of effect size.
Subgroup analysis was done according to a diagnostic method, type of study, and continents. Meta-regression was used to explore relationship between prevalence of $C T$ associated with preterm delivery including the year of the study and sample size. To find association between Chlamydia infections and the risk of preterm delivery, an odds ratio (OR) was used and statistical analyses were performed in STATA version 11.1 and metan commend.

\section{Results}

We used 23 relevant studies (1986-2014) were included in this meta-analysis (Additional file 1.). The overall relatedness of $C T$ infections with preterm delivery was estimated to be $0.13 \%$ (CI 95\%: 0.11-0.16) (Fig. 2). The prevalence of $C T$ infections with preterm delivery based on the study method including PCR [0.06 (CI 95\%: 0.04-0.09)], serology [0.23 (CI 95\%: 0.10-0.35)], and culture [0.17 (CI 95\%: 0.10-0.24)]. The prevalence of CT infections leading to preterm deliveries based on study type including case-control [0.16 (CI 95\%: 0.11-0.21)] and cross-sectional [0.13 (CI 95\%: 0.08-0.17)] was determined. The prevalence of $C T$ infections leading to preterm delivery based on geographical location including Europe [0.13 (95\% CI: 0.09-0.18)], Asia [0.08 (CI 95\%: -

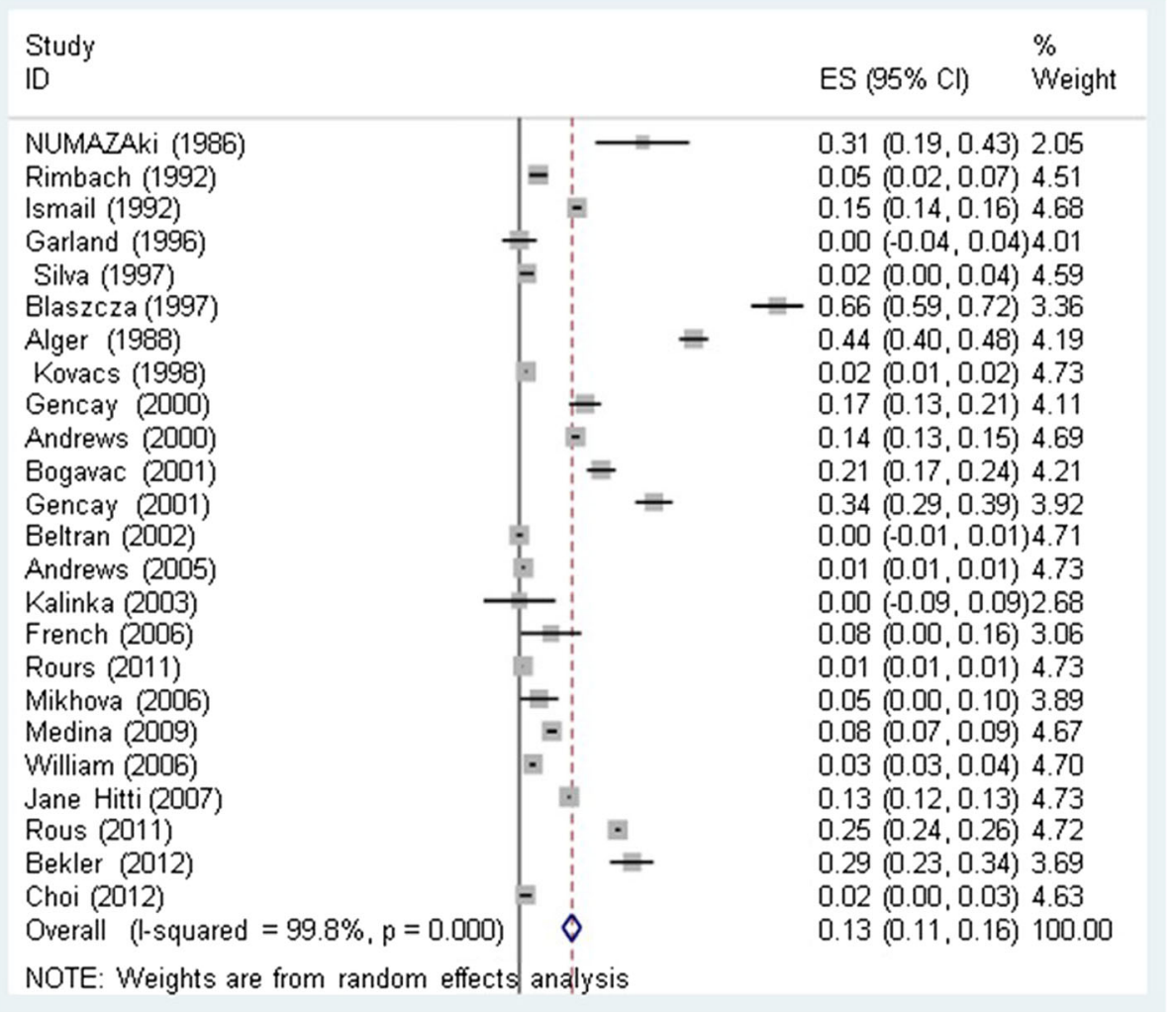

Fig. 2 Prevalence of CT infections with preterm births and its 95\% confidence interval using a random-effect model. Midpoint of each line segment represents the estimated prevalence in the study. Rhombic mark shows the prevalence in Total, extracted from all studies 
0.01-0.17)], the USA [0.15 (CI 95\%: 0.08-0.22)], and Africa [0.29 (CI 95\%: 0.23-0.34)] were estimated (Table 1). Analysis showed that pregnant women with chlamydia infections were 2.28 times more likely to deliver prematurely in comparison to those who were not infected.

We can conclude that chlamydia colonization increased the risk of premature labor, OR $=2.16$ (CI 95\%: 1.3-3.57) (Fig. 3). For OR analysis, random effect models were used. $\mathrm{I}^{2}$ was significant $(p=0.013)$.

Our interpretation of the meta-regression data showed that there was no significant relationship between the prevalence of $C T$ and preterm delivery with the year of study $(p=0.33)$ and sample size $(p=0.21)$ (Figs 4 and 5).

According to our analysis as publication bias, there were no significant biases in these studies. In fact, most studies were located inside our funnel plot and the results were included in our analysis (Fig. 6).

\section{Discussion}

Chlamydia trachomatis is an intracellular pathogen and immunologic response to $C T$ infection elaborate $\mathrm{T}$ cell response and cytokine release. Because inflammatory reactions induce damage in tissue, preterm birth may be the consequence of those inflammatory responses $[17,18,25,30,35]$. In this meta-analysis, it turned out that there is a significant relationship between $C T$ infections and preterm delivery. Our interpretation of the
Table 1 Prevalence of $C T$ infection with preterm delivery according to different factors

\begin{tabular}{lllll}
\hline & & Study NO. & Prevalence $(95 \%$ Cl) & Weight \% \\
\hline Diagnostic & PCR & 10 & $0.06(0.04-0.09)$ & 45.50 \\
method & Serology & 8 & $0.23(0.10-0.35)$ & 27.90 \\
& Culture & 6 & $0.17(0.10-0.24)$ & 26.60 \\
& Total & 24 & $0.13(0.11-0.24)$ & 100 \\
Study type & Case - & 9 & $0.16(0.11-0.21)$ & 36.67 \\
& control & & & \\
& Sectional & 15 & $0.13(0.08-0.17)$ & 66.33 \\
& Total & 24 & $0.13(0.11-0.24)$ & 100 \\
Continent & Europe & 14 & $0.13(0.09-0.18)$ & 59.55 \\
& Asia & 3 & $0.08(-0.01-0.17)$ & 10.70 \\
& USA & 6 & $0.15(0.08-0.22)$ & 20.06 \\
& Africa & 1 & $0.29(0.23-0.34)$ & 3.69 \\
& Total & 24 & $0.13(0.11-0.24)$ & 100 \\
Recognize & NO & 14 & $0.04(0.02-0.05)$ & 57.08 \\
group & Yes & 10 & $0.26(0.19-0.33)$ & 42.92 \\
& Total & 24 & $0.13(0.11-0.24)$ & 100 \\
\hline
\end{tabular}

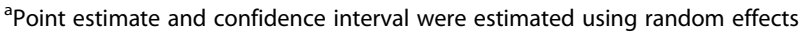
model

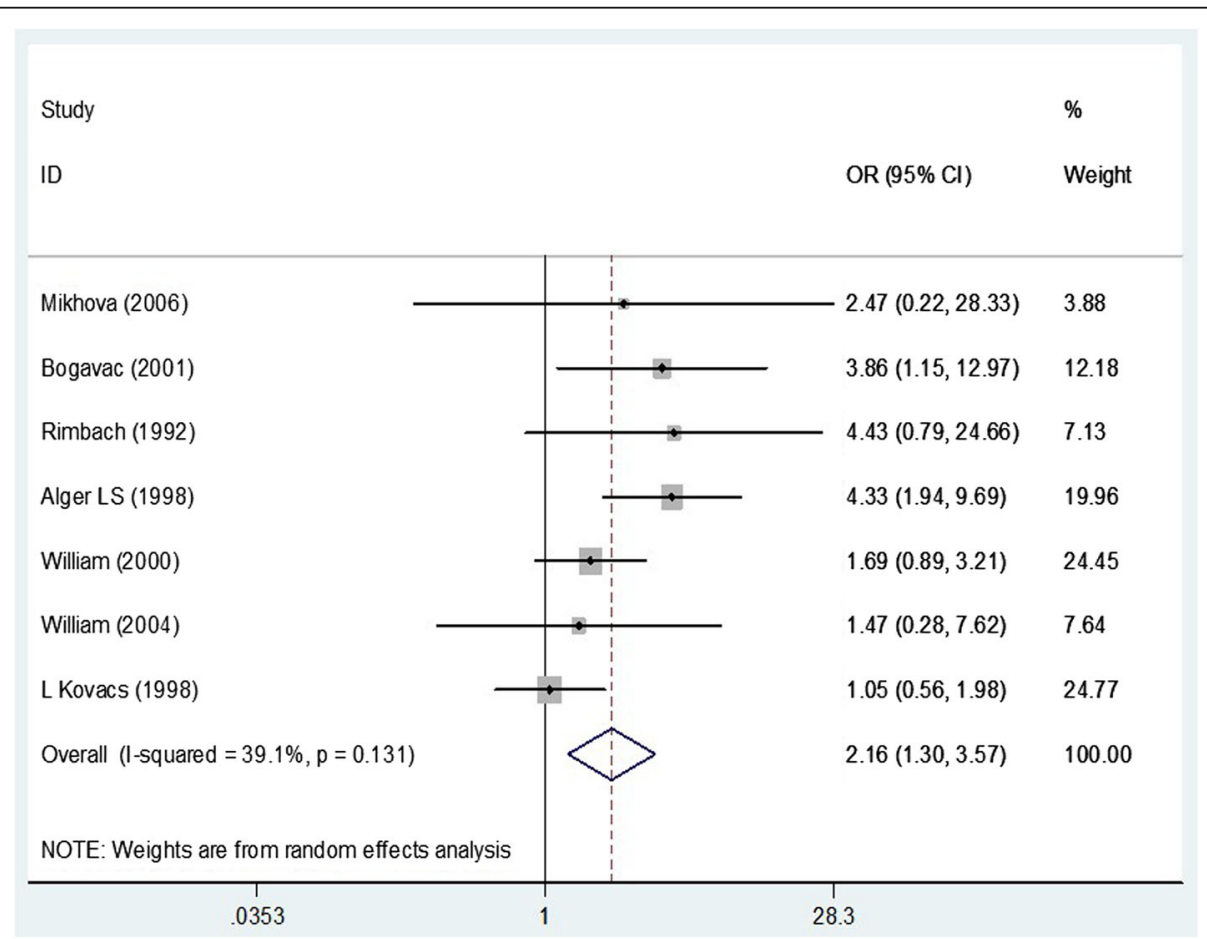

Fig. 3 Meta-analysis of the association of CT infections with preterm delivery risk. Odds Ratio and 95\% confidence intervals for each study and in summary with weighting in a random-effect model are shown. Midpoint of each line segment represents the estimated OR in the study. Rhombic mark shows the OR in Total, extracted from all studies 


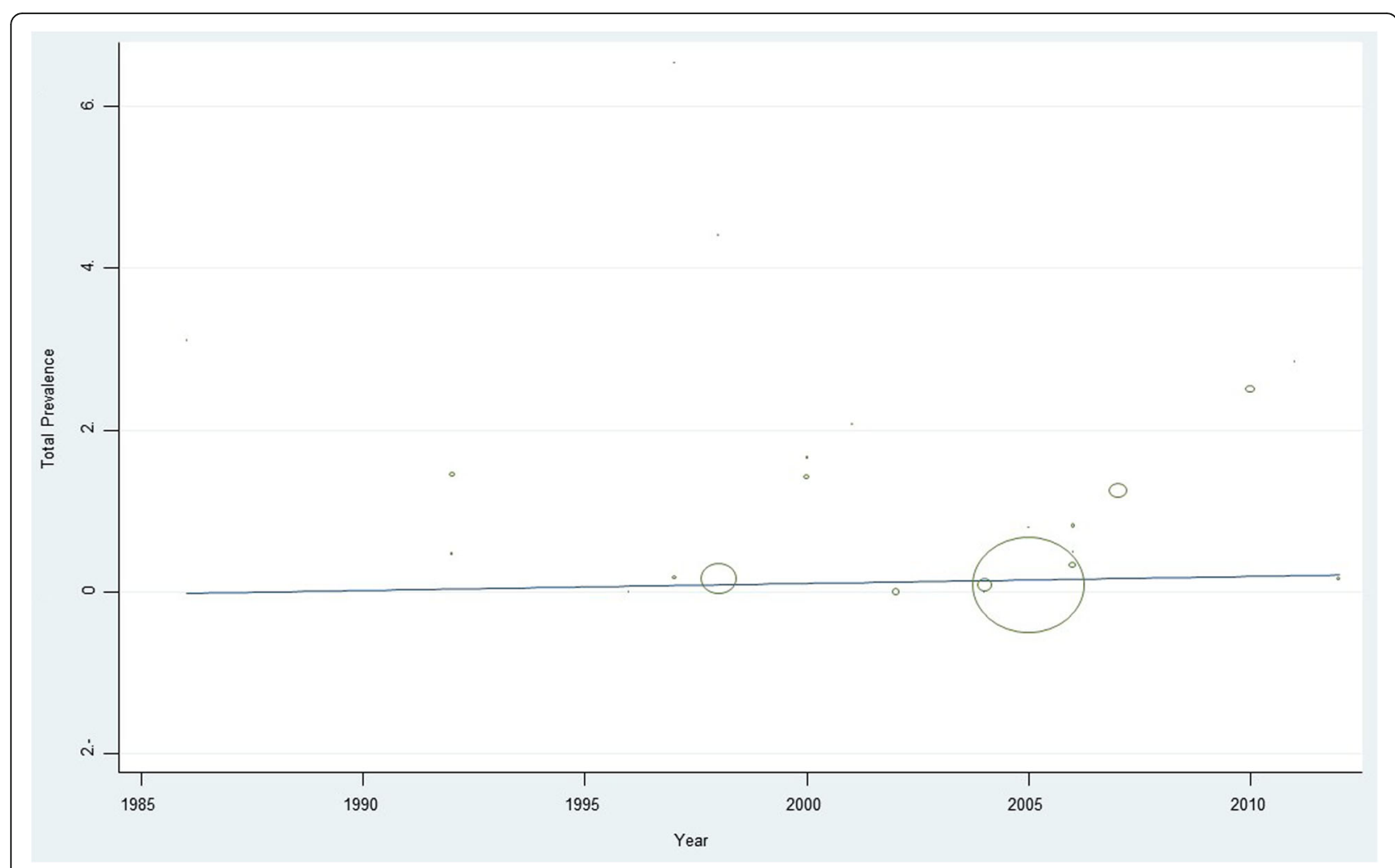

Fig. 4 Meta-regression of $C T$ infections with preterm delivery prevalence with year of data collection as variable

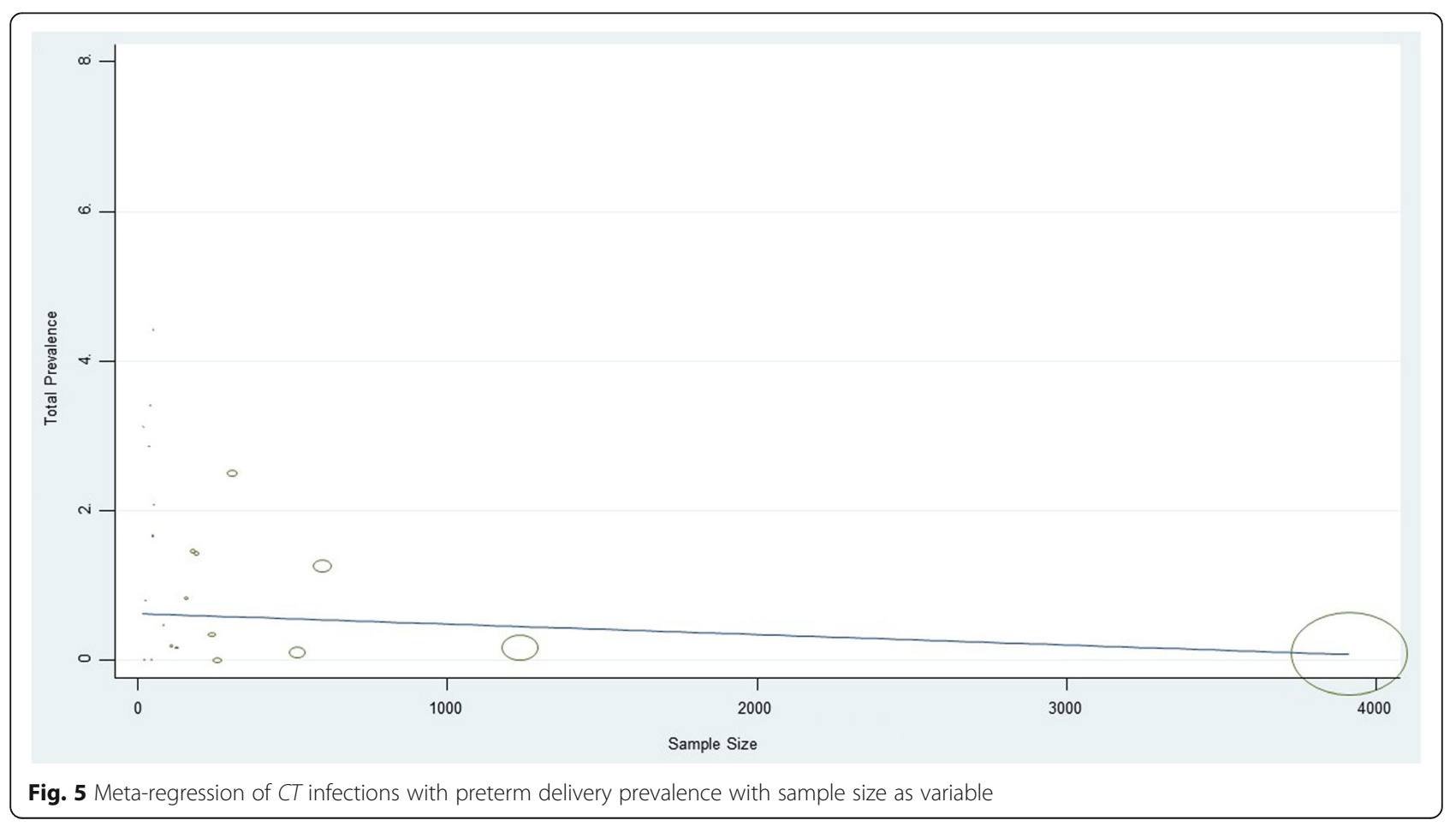


Begg's funnel plot with pseudo $95 \%$ confidence limits

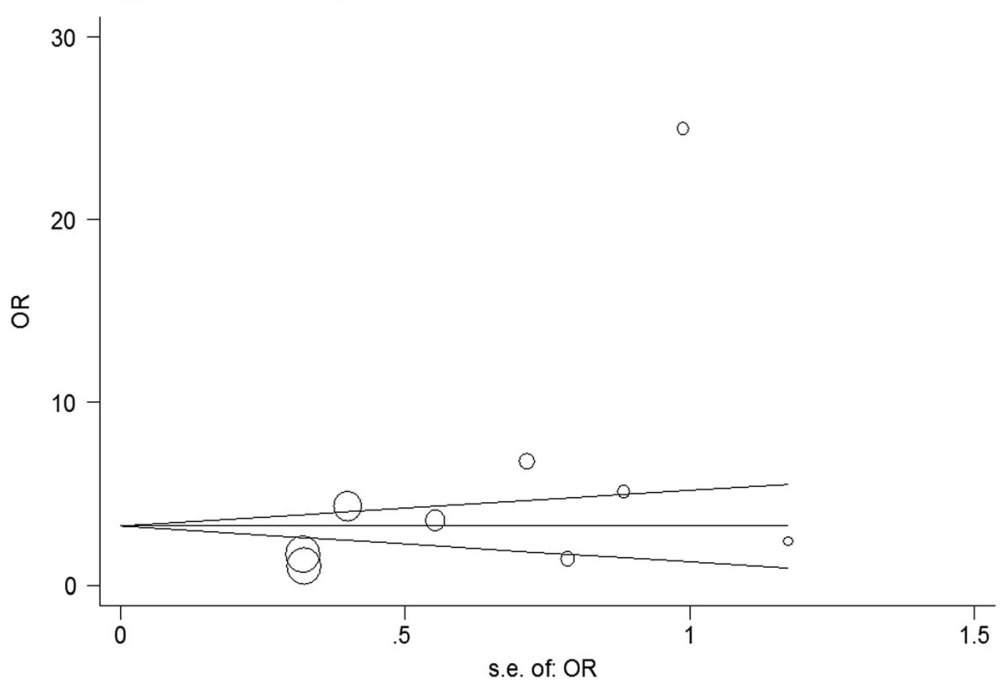

Fig. 6 Begg's funnel plot for publication bias in the risk difference (RD) analysis. The diameter of each circle represents the weight in the meta-analysis

meta-regression showed that there was no significant relationship between prevalence of $C T$ infections and preterm delivery with the year of study $(p=0.33)$ and sample size $(p=0.21)$. The prevalence of $C T$ infections and preterm delivery in Europe and America was relatively high. Among the articles that were studied, we noted some contradictory results. In Mikhova et al. (2006) using PCR methodology found that there was no relationship between $C T$ infections and preterm birth observed [26]. Another PCR study by William et al. (2000) showed that there was a connection between $C T$ infection and preterm birth [18]. In a cross sectional study using culture technique, Ismail et al. (1992) reported a meaningful correlation between Chlamydia trachomatis infections and preterm birth [10]. In another cross sectional study by Silva et al. (1997) using bacterial cultures observed no correlation between $C T$ infection and preterm birth [12]. Bogavac et al. (2001) showed that a significant relationship between the $C T$ infection and preterm birth was observed in a case-control study using serology [19]. Rimbach et al. (1992) using the same method, showed no connection between preterm birth and Chlamydia trachomatis infections [9]. In regard to the overall results based on studies performed on diverse populations, this meta- analysis showed a clear association between preterm delivery and prior colonization with Chlamydia trachomatis.

\section{Conclusions}

In regard to the results of numerous studies performed on different continents, this meta-analysis showed a clear association between preterm delivery and prior $C T$ colonization.

\section{Additional file}

Additional file 1: Summary of the included studies evaluating the prevalence of CT infections with preterm deliveries. (XLSX $14 \mathrm{~kb}$ )

\section{Abbreviations \\ CT: Chlamydia trachomatis; MH: Mycoplasma huminis; MU: Mycoplasma urealyticum; NG: Neisseria gonorrhea; TV: Trichomonas vaginal}

\section{Acknowledgements}

We would like to thank Kurdistan University of Medical Sciences and Research Deputy of Kurdistan University of Medical Sciences and Cellular and Molecular Research Center Research Institute for Health Development, of Kurdistan University for financial support.

\section{Funding}

This study is funded by Kurdistan University of Medical Sciences. The funding body managed the reviewing proposal of this study and they did not have any role in data collection, analysis, and interpretation of data and in writing this manuscript.

\section{Availability of data and materials}

All data generated or analyzed during this study are included in this published article.

\section{Authors' contributions}

AA carried out the study and collected data. RR supervised the study, participated in designing and conducting it, and prepared the original version of the manuscript. KS and FS conducted research and performed the statistical analysis. NA and AM conducted research and revised the manuscript. All authors studied and approved the content of the present manuscript and participated in revising the paper.

Ethics approval and consent to participate Not applicable.

Competing interests

The authors declare that there are no conflicts of interest regarding the publication of this article.

\section{Publisher's Note}

Springer Nature remains neutral with regard to jurisdictional claims in published maps and institutional affiliations. 


\section{Author details}

Cellular and Molecular Research Center, Research Institute for Health Development, Kurdistan University of Medical Sciences, Pasdaran Street, Sanandaj 66177-13446, Iran. ${ }^{2}$ Microbiology Department, Faculty of Medicine, Kurdistan University of Medical Sciences, Sanandaj, Iran. ${ }^{3}$ Psychosocial Injuries Research Center, llam University of Medical Sciences, Ilam, Iran. ${ }^{4}$ Proteomics Research Center, Shahid Beheshti University of Medical Sciences, Tehran, Iran. ${ }^{5}$ Microbiology Department, School of Medicine, Iran University of Medical Sciences, Tehran, Iran

\section{Received: 11 April 2018 Accepted: 31 May 2018}

\section{Published online: 18 June 2018}

\section{References}

1. Stamm WE, Jones R, Batteiger B: Chlamydia trachomatis (Trachoma, perinatal infections, lymphogranuloma venereum, and other genital infections). In: Principles and practice of infectious diseases, . Edited by Mandell GL, Dolin R, JE B. Issue 2. Philadelphia: Elsevier Churchill Livingstone; 2005. pp. 2239.

2. Sciarra JJ. Sexually transmitted diseases: global importance. Int J Gynaecol Obstet. 1997;58(1):107-19.

3. Duncan B, Hart G. Sexuality and health: the hidden costs of screening for chlamydia trachomatis. Br Med J. 1999;318(7188):931-3.

4. Workowski K, Levine W, Wasserheit J. Centers for Disease Control and Prevention, Atlanta, Georgia. US Centers for Disease Control and Prevention guide-lines for the treatment of sexually transmitted diseases: an opportunity to unify clinical and public health practice. Ann Intern Med. 2002;137(4):255-62.

5. McGregor J, French J. Chlamydia trachomatis infection during pregnancy. Am J Obstet Gynecol. 1991:164(6 Pt 2):1782-9.

6. Kamal S, Sharan A, Kumar U, Shahi S. Serum magnesium level in preterm labour. Indian J Pathol Microbiol. 2003;46(2):271-3.

7. Beigi $\mathrm{A}$, Taheri $\mathrm{N}$, Norouzi $\mathrm{H}$. The prevalence of very preterm deliveries, risk factors, and neonatal complications in Arash women hospital: a brief report. Tehran University Med J. 2013:71(3):194-8.

8. Cunningham CF, Leveno K, Bloom S, Hauth J, Rouse D, Cy S. Williams Obstetrics. vol. 36. 23rd ed. New York: McGraw-Hill; 2010. p. 804-20.

9. Rimbach S, Wallwiener D, Baier S, Piotrowski T, Engel K, Näher H, Bastert G. chlamydia trachomatis: screening within the scope of prenatal care and rapid diagnosis in threatened premature labor. Zentralblatt fur Gynakologie. 1992;115(11):478-82

10. Ismail MA, Pridjian G, Hibbard JU, Harth C, Moawad AA. Significance of positive cervical cultures for chlamydia trachomatis in patients with preterm premature rupture of membranes. Am J Perinatol. 1992:9(05/06):368-70.

11. Garland SM, Bowman ED. Role of Ureaplasma urealyticum and chlamydia trachomatis in lung disease in low birth weight infants. Pathology. 1996; 28(3):266-9.

12. DA SILVA O, Gregson D, Hammerberg O. Role of Ureaplasma urealyticum and chlamydia trachomatis in development of bronchopulmonary dysplasia in very low birth weight infants. Pediatr Infect Dis J. 1997:16(4):364-9.

13. Błaszczak I, Barłowska Z, Lubera K, Rzeszutek K. chlamydia trachomatis in imminent premature deliveries. Polski merkuriusz lekarski: organ Polskiego Towarzystwa Lekarskiego. 1997;3(17):234-5.

14. Alger LS, Lovchik JC, Hebel JR, Blackmon LR, Crenshaw MC. The association of Chlamydia trachomatis, Neisseria gonorrhoeae, and group B streptococci with preterm rupture of the membranes and pregnancy outcome. Am J Obstet Gynecol. 1988;159(2):397-404.

15. Kovacs L, Nagy E, Berbik I, Meszaros G, Deak J, Nyari T. The frequency and the role of chlamydia trachomatis infection in premature labor. Int $J$ Gynecol Obstet. 1998;62(1):47-54

16. Gencay $M$, Koskiniemi $M$, Ämmälä $P$, Fellman $V$, Närvänen $A$, Wahlström $T$, Vaheri A, Puolakkainen M. Chlamydia trachomatis seropositivity is associated both with stillbirth and preterm delivery. Apmis. 2000;108(9):584-8.

17. Gencay M, Koskiniemi M, Fellman V, Ämmälä P, Vaheri A, Puolakkainen M. Chlamydia trachomatis infection in mothers with preterm delivery and in their newborn infantsNote. Apmis. 2001;109(9):636-40.

18. Andrews WW, Goldenberg RL, Mercer B, lams J, Meis P, Moawad A, Das A, VanDorsten JP, Caritis SN, Thurnau G. The preterm prediction study: association of second-trimester genitourinary chlamydia infection with subsequent spontaneous preterm birth. Am J Obstet Gynecol. 2000;183(3): $662-8$.
19. Bogavac M, Aleksić S, Radulović A. chlamydia trachomatis-a possible cause of premature labor. Med Pregl. 2001:55(3-4):146-8.

20. Beltrán MJ, Avila-Vergara M, Vadillo-Ortega F, Hernández-Guerrero C, PerazaGaray F, Olivares-Morales S. Cervicovaginal infection as a risk factor for premature labor. Ginecologia y obstetricia de Mexico. 2002;70:203-9.

21. Andrews WW, Goldenberg RL, Hauth JC, Cliver SP, Conner M, Goepfert AR. Endometrial microbial colonization and plasma cell endometritis after spontaneous or indicated preterm versus term delivery. Am J Obstet Gynecol. 2005;193(3):739-45.

22. Kalinka J, Laudański T, Hanke W, Krzemiński Z, Wasiela M. The evaluation of prevalence and the impact of pathological mi-CROFLORA of the lower genital tract among women at early pre-GNANCY on the risk of preterm delivery. Medycyna Doświadczalna. 2003:55(3):283.

23. French $\mathrm{J}, \mathrm{McGregor} J \mathrm{~A}$, Parker R. Readily treatable reproductive tract infections and preterm birth among black women. Am J Obstet Gynecol. 2006;194(6):1717-26.

24. Rours GIJ, de Krijger RR, Ott A, Willemse HF, de Groot R, Zimmermann L, Kornelisse RF, Verbrugh HA, Verkooijen RP. Chlamydia trachomatis and placental inflammation in early preterm delivery. Eur J Epidemiol. 2011;26(5):421-8

25. Rours GIJ, Duijts L, Moll HA, Arends LR, de Groot R, Jaddoe WW, Hofman A, Steegers EA, Mackenbach JP, Ott A. Chlamydia trachomatis infection during pregnancy associated with preterm delivery: a population-based prospective cohort study. Eur J Epidemiol. 2011:26(6):493-502

26. Mikhova M, Ivanov S, Nikolov A, Mitov I, lordanov D, Uzunova V, Shopova E. Cervicovaginal infections during pregnancy as a risk factor for preterm delivery. Akusherstvo i ginekologiia. 2006;46(9):27-31.

27. Medina M, Moya W, Hidalgo L, Calle A, Terán E, Chedraui P. Molecular identification of endocervical chlamydia trachomatis infection among gestations at risk for preterm birth in Ecuador. Arch Gynecol Obstet. 2009; 279(1):9-10.

28. Andrews WW, Klebanoff MA, Thom EA, Hauth JC, Carey JC, Meis PJ, Caritis SN, Leveno KJ, Wapner RJ, Varner MW. Midpregnancy genitourinary tract infection with chlamydia trachomatis: association with subsequent preterm delivery in women with bacterial vaginosis and trichomonas vaginalis. Am J Obstet Gynecol. 2006;194(2):493-500.

29. Hitti J, Nugent R, Boutain D, Gardella C, Hillier SL, Eschenbach DA. Racial disparity in risk of preterm birth associated with lower genital tract infection. Paediatr Perinat Epidemiol. 2007;21(4):330-7.

30. Bekler C, Kultursay N, Ozacar T, Sayiner A, Yalaz M, Akisu M. Chlamydial infections in term and preterm neonates. Jpn J Infect Dis. 2012;65(1):1-6.

31. Choi SJ, Park SD, Jang IH, Uh Y, Lee A. The prevalence of vaginal microorganisms in pregnant women with preterm labor and preterm birth. Annals of laboratory medicine. 2012;32(3):194-200.

32. Liberati A, Tetzlaff J, Mulrow C, Gøtzsche P, loannidis J, Devereaux C, Kleijnen D, Moher D. The PRISMA statement for reporting systematic reviews and meta-analyses of studies that evaluate healthcare interventions: explanation and elaboration. PLoS Med. 2009:6(7):e1000100.

33. Babaknejad N, Sayehmiri F, Sayehmiri K, Rahimifar P, Bahrami S, Delpesheh A, Hemati F, Alizadeh S. The relationship between selenium levels and breast cancer: a systematic review and meta-analysis. Biol Trace Elem Res. 2014;159(1-3):1-7

34. Sayehmiri F, Kiani F, Sayehmiri K, Soroush S, Asadollahi K, Alikhani MY, Delpisheh A, Emaneini M, Bogdanovic L, Varzi AM. Prevalence of cagA and vacA among helicobacter pylori-infected patients in Iran: a systematic review and meta-analysis. The Journal of Infection in Developing Countries. 2015:9(07):686-96

35. Currie MJ, Bowden FJ. The importance of chlamydial infections in obstetrics and gynaecology: an update. Aust N Z J Obstet Gynaecol. 2007:47(1):2-8. 